Open access publishing

\section{The Journal of medical genetics and open access publishing: to choose or not to choose?}

\section{Eamonn R Maher}

\section{The Journal of medical genetics moves towards open access publishing}

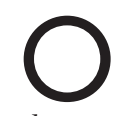

pen access publishing, broadly defined as content that is freely available on the Internet without the need of a subscription or payment, is the hot topic in journalology. Advocates of open access publishing have been buoyed by the agreement to fund publication charges by large agencies, such as the US National Institutes of Health, the Howard Hughes Medical Institute, and the Wellcome Trust. The open access model of publishing depends on switching publication costs from the current subscription model ("reader pays") to researchers ("author pays"). There are clear advantages in increasing accessibility to their research findings for well-funded research groups, particularly those funded by agencies that are committed to paying publication charges in open access journals. However, for some researchers, especially clinical researchers without large grants, there has been concern about the cost of publishing a paper in an open access journal - some journals have cited costs in the region of $\$ 3000$. Furthermore, publishers have expressed concern that they will lose subscriptions to non-open access journals, leading to journals closing and reduced opportunities for publication.

The Journal of Medical Genetics (JMG) is published by the BMJ Publishing Group Ltd (BMJPG), whose mission is "To publish intellectually sound material that will serve the needs of doctors, members, other health professionals, the scientific community, and the pub-

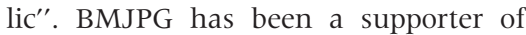
open access publishing and the flagship general medical journal, the $B M J$, has been freely available since 1995 (www.bmj.com). In 2005, the business model for bmj.com will change: original articles will remain freely available in perpetuity but other material will be behind access controls after being free for its first week of publication. Furthermore all online content in the $B M J$ and its 22 sister specialist medical journals is freely available to everyone in developing world countries (as defined by the Health Inter Network for Research initiative (HINARI)) and all material over one year old is free to all. Nevertheless the challenge for BMJPG and all publishers is how to make open access a financially viable business model. One suggestion is where a journal might publish original research on an open access/author pays basis, but non-original research articles, such as editorials and reviews, are only available to subscribers. A further model is an "author chooses" system, in which authors can either pay publication fees to make their article open access or publish conventionally so that only subscribers have access.

This year the $J M G$ will experiment with open access. This will take two forms: (1) During 2005, up to 20 papers from the UK will be published as open access articles at no cost to the authors; suitable papers accepted will be randomised to "open access" or "closed access". This has been made possible by financial support from the Joint Information Systems Committee (JISC), a joint body of the Further and Higher Education Funding Councils of the UK. More information about JISC and its commitment to funding "an
Open Access Initiative" can be found on its website: http://www.jisc.ac.uk. (2) Authors from countries other than the UK will be able to choose to pay a publication fee $(£ 1200(\$ 2300))$ to make their article freely available to all. If they decline, the article will remain behind access controls until it is 12 months old, but will be free thereafter as is our usual practice. Do note however that although any open access article is free for research and personal use, our reuse policy remains unchanged. Full details of this policy can be found on our website (http://jmg.bmjjournals.com/ misc/ifora/licence.shtml).

To discover whether the "author chooses" model makes a difference to the level of use of these articles, we will:

- Compare the number of citations to closed and open access articles

- Compare the number of hits and downloads on the website to the previous year for open and closed access articles

- Investigate whether open access had any effect on submissions compared with 2004 and 2003

- Survey all authors to assess

- their experience with $J M G$

- whether they would or could pay in the future

- whether they felt exposure to their work was better under an open access model

- their views on the "author chooses" model

- Conduct focus group research with all accepted UK authors to assess the same factors

If this experiment with open access is successful, we anticipate a gradual transition in which author publication fees will allow subscription rates to be reduced as the journal becomes increasingly open access. Geneticists are used to living in times of change and it seems that this applies not only to our clinical and scientific research activities but also to the journal we read and publish in!

J Med Genet 2005;42:97.

doi: 10.1136/jmg.2004.030239

Correspondence to: E R Maher, Birmingham, UK; ermaher@hgmp.mrc.ac.uk 